\title{
A comparison of instrumental reward and avoidance training with classical reinforcement technique in conditioning the eyelid response'
}

\author{
Wesley J. Hansehe, TULANE UNIVERSITY \\ David A. Grant, UNIVERSITY OF WISCONSIN
}

\begin{abstract}
Successful conditioning of the human eyelid response is reported, using intrumental reward training. Instrumental reward training of the eyelid appears to lead to more resistance to extinction than that found following classical or avoidance training. When reward training is added to avoidance training resistance to extinction is increased, but no corresponding effect is found when reward training is added to classical reinforcement.

The eyelid response is readily conditioned by classical methods where the delivery of the UCS, usually an airpuff to the cornea, is not contingent upon the S's response. Successful instrumental avoidance training has also been reported for the eyelid response by Logan (1951) and Kimble, Mann \& Dufort (1955). Although the journals contain numerous instances of instrumental reward conditioning of human responses, earlier unpublished exploratory work using verbal instructions and reinforcement was unsuccessful in conditioning the eyelid response in the Wisconsin laboratory.

The present study reports a successful application of instrumental reward training with symbolic reinforcement of the eyelid response, a comparison of instrumental reward and avoidance training with classical eyelid conditioning, and an investigation of the addition of instrumental reward reinforcement to avoidance and classical training of the eyelid.
\end{abstract}

\section{Method}

The basic apparatus and procedure was the same as that described by Hartman \& Grant (1962). The $\mathrm{S}$ sat looking into a rectangular wooden enclosure, painted flat white, and illuminated to approximately 10 $\mathrm{ml}$, so as to avoid dark adaptation. The $\mathrm{S}$ wore a modified basketball spectacle protector carrying the air jet, and microtorque potentiometer which was coupled to his eyelid by means of a wire, hypodermic tube, and Scotch tape. The CS was always a $1 \mathrm{sec}$. illumination of a $10 \mathrm{~cm}$ diameter circular ground glass window to $42 \mathrm{ml}$. The classical UCS, when given, consisted of a puff of nitrogen delivered to the cornea $660 \mathrm{msec}$. after onset of the CS. The puff duration was $100 \mathrm{msec}$. and the pressure at the source was $150 \mathrm{~mm}$ of $\mathrm{Hg}$. The eyelid response and its first time-derivative were recorded by an inkwriting system. A voltage level pickoff unit operated a relay $.05 \mathrm{sec}$. after the derivative voltage reached a low preset level.

Timing circuits were arranged so that if a new or additional eyelid closure occurred between $200 \mathrm{msec}$. and $660 \mathrm{msec}$. after onset of the CS, the relay operation could be used to: (a) eliminate the presentation of the UCS, (b) provide a symbolic reward reinforcement for the response by means of illuminating a 50 watt bulb and operating a Veeder-Root electric counter in the direct view of the S, or (c) provide both UCS elimination plus symbolic reward reinforcement. In the classical conditioning procedure, the pickoff unit was not activated.

All Ss received 60 acquisition trials followed by 25 extinction trials. The intertrial interval was varied randomly from 16 to $48 \mathrm{sec}$. and averaged $32 \mathrm{sec}$. The experimental design was an orthogonal variation of symbolic reward reinforcement (present or absent) with UCS contingency (classical or noncontingent, avoidance or response-contingent, and no UCS). There were thus six experimental procedures, and 15 men and women students from Introductory Psychology classes were randomly assigned to each procedure.

If symbolic reward training was to be used, the $\mathrm{S}$ was instructed, "I cannot tell you what you are supposed to do but I can say that when you have done the right thing the light bulb will light. When you have made a correct response the light bulb will light, and the counter will count the number of times the light bulb goes on." If symbolic reinforcement was not to be given, the $\mathrm{S}$ was given standard neutral instructions not to control his natural responses to the stimuli-to let his responses take care of themselves.

\section{Hesults}

A CR was defined as any response of greater than one $\mathrm{mm}$ recorded magnitude which occurred in the interval from $200 \mathrm{msec}$. after the onset of the CS and before the onset of the UCS. Acquisition and extinction curves for all groups are plotted in Fig. 1a, 1b, and 1c. Percent CRs are plotted in 10-trial blocks during acquisition and 5-trial blocks during extinction. The initial point on all acquisition curves was computed from mean performance on the first two trials.

Figure 1a shows that acquisition with symbolic reward training was intermediate between the superior acquisition with classical UCS training and the inferior acquisition with avoidance training. The latter result has been found by Logan (1951) and Kimble et al (1955). Resistance to extinction seems greatest following symbolic training. In Fig. $1 \mathrm{~b}$ it is apparent that addition 

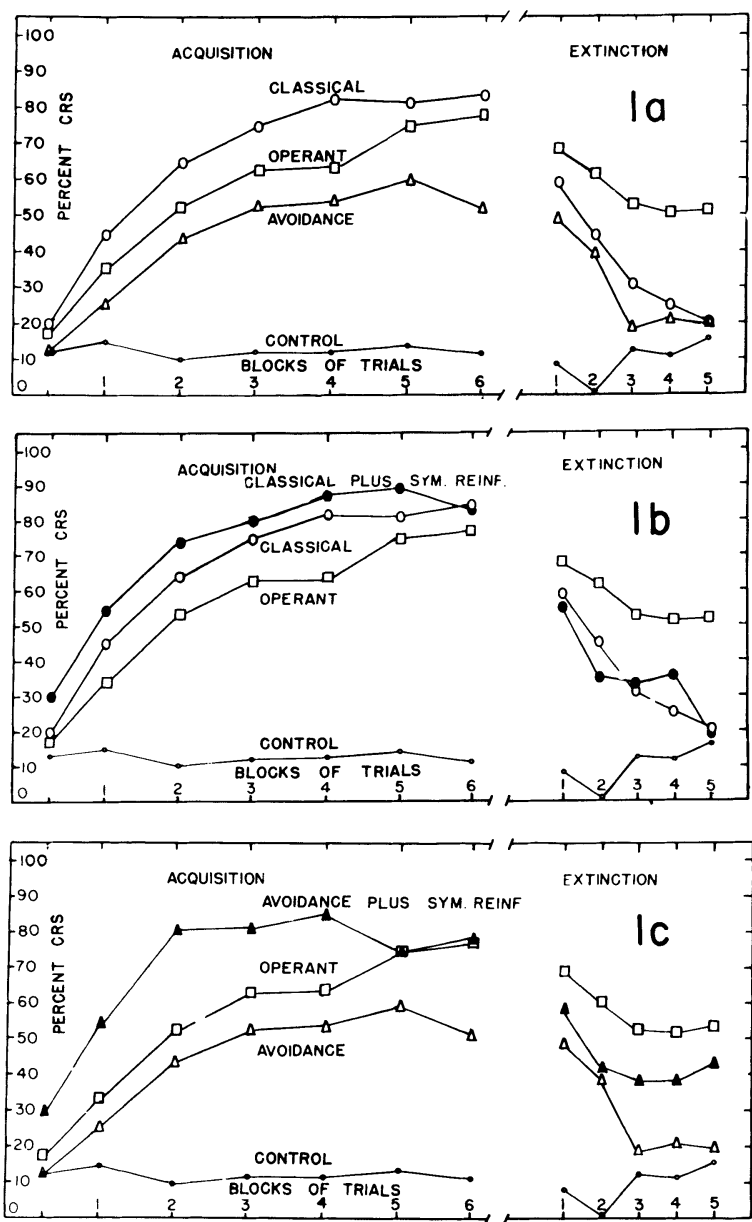

Fig. 1. Acquisition and extinction curves for eyelid responses under six conditions of training.

of symbolic reward training to classical training increased rate of acquisition slightly but seems to have no effect upon extinction, which resembles extinction following classical training alone more than it resembles extinction following reward training alone. In contrast, Fig. 1c shows that adding symbolic reward training to avoidance training leads to greater resistance to extinction than that produced by avoidance training alone. In the analyses of variance of total acquisition performance and total extinction performance all main effects and interactions except one in extinction were statistically significant, but the extinction differences disappeared when analysis of covariance was used to control for final level of responding in acquisition.

\section{Diseussion}

The primary novel result of the experiment was the successful symbolic reward training of the eyelid response by means of a simple procedure. The eyelid responses, thus produced, closely resembled the eyelid CRs occurring with classical airpuff reinforcement, although there was more voluntary form responses (Spence \& Ross, 1959) than in the classical group. ${ }^{2}$ This finding is extremely useful when for theoretical reasons a non-aversive reinforcement procedure need be used with the eyelid response. This success in reward training is probably due to the immediacy of the reinforcement.

A second noteworthy feature of the results is that the eyelid CR appears to be relatively resistant to extinction following symbolic reward training.

Finally, although this result was not statistically significant, there was some indication that symbolic reward training added to avoidance training increased resistance to extinction. In contrast, when symbolic reward training was added to classical training, no increase in resistance to extinction was found. The distribution of latencies and the form of the responses in avoidance training showed a high instance of voluntary responding (Spence \& Ross, 1959) in contrast to a relatively low rate of voluntary responding in the classically conditioned group. It is tentatively suggested that if the UCS mode of reinforcement tends to produce voluntary responding, symbolic reward training is especially effective in making the resulting response resistant to extinction, whereas if the mode of training does not produce many voluntary form responses, the addition of symbolic reinforcement has relatively little effect upon extinction.

\section{References}

HARTMAN, T. F。, \& GRANT, D. A. Effects of pattern of reinforcement and verbal information on acquisition, extinction, and spontaneous recovery of the eyelid CR. J. exp. Psychol., 1962, 63, 217-226.

KIMBLE, G。A., MANN, L。 I., \& DU FORT, R. H. Classical and instrumental eyelid conditioning. J. exp. Psychol., 1955, 49, 407-417.

LOGAN, F. A. A comparison of avoidance and non-avoidance eyelid conditioning. J. exp. Psychol., 1951, 42, 390-393.

SPENCE, K。 W., \& ROSS, L。 E. A methodological study of the form and latency of eyelid responses in conditioning. J. exp. Psychol., 1959, 58, 376-385.

Notes

1. The present paper is a condensed version of the Ph. D. thesis presented by Dr. Wesley J. Hansche to the University of Wisconsin in 1959. Additional analyses were carried out subsequently by the junior author and the present manuscript was prepared by him. The research was supported in part by grants to the junior author from the Graduate Research Committee of the University of Wisconsin and the National Institutes of Health.

2. The authors are indebted to Dr. Thomas F. Hartman and Mr. Robert A. Fleming for further analyses on the original data. 